D. Konrad - A. Rudich - P. J. Bilan · N. Patel •

C. Richardson - L. A. Witters - A. Klip

\title{
Troglitazone causes acute mitochondrial membrane depolarisation and an AMPK-mediated increase in glucose phosphorylation in muscle cells
}

Received: 24 August 2004 / Accepted: 8 December 2004 / Published online: 15 April 2005

(C) Springer-Verlag 2005

\begin{abstract}
Aims/hypothesis: Troglitazone was the first thiazolidinedione (TZD) approved for clinical use, exerting hypoglycaemic effects related to its action as a ligand of the peroxisome proliferator-activated receptor $\gamma$ receptor in adipocytes. However, emerging evidence suggests that mitochondrial function may be affected by troglitazone, and that skeletal muscle cells acutely respond to troglitazone by enhancing glucose uptake. The aim of the present study was to determine the cellular mechanisms by which troglitazone acutely stimulates glucose utilisation in skeletal muscle cells. Methods: L6 cells overexpressing GLUT4myc were incubated with troglitazone. Glucose uptake, transport and phosphorylation as well as AMP-activated protein kinase (AMPK) signalling and insulin signalling were examined. Changes in mitochondrial membrane potential were measured using the J-aggregate-forming dye JC-1. AMPK signalling was interfered with using AMPK $\alpha 1 / \alpha 2$ siRNA. Results: Troglitazone acutely (in $10 \mathrm{~min}$ ) reduced the
\end{abstract}

D. Konrad · A. Rudich · P. J. Bilan · N. Patel · A. Klip $(\bowtie)$

Programme in Cell Biology,

Hospital for Sick Children,

555 University Avenue,

Toronto, ON, M5G 1X8, Canada

e-mail: amira@sickkids.ca

Tel.: +1-416-8136392

Fax: +1-416-8135028

D. Konrad

Department of Endocrinology and Diabetology,

University Children's Hospital,

Zurich, Switzerland

\section{A. Rudich}

The S. Daniel Abraham Center for Health and Nutrition,

Department of Clinical Biochemistry,

Faculty of Health Sciences,

Ben-Gurion University,

Beer-Sheva, Israel

C. Richardson · L. A. Witters

Endocrine-Metabolism Division,

Departments of Medicine and Biochemistry,

Dartmouth Medical School,

Hanover, NH, USA mitochondrial membrane potential in L6GLUT4myc myotubes and robustly stimulated AMPK activity. Following 30 min of incubation with troglitazone or insulin, 2-deoxyglucose uptake was stimulated 1.5- and 2.1-fold respectively, and in cells treated with troglitazone, a 1.8-fold increase in the 2-deoxyglucose-6-phosphate:2-deoxyglucose ratio was observed. Moreover, contrary to insulin, troglitazone did not significantly stimulate 3-O-methylglucose uptake. Unlike insulin, troglitazone did not increase surface GLUT4myc content and did not increase IRS1associated phosphatidylinositol 3-kinase activity or Akt phosphorylation on T308 and S473. Interestingly, interfering with troglitazone-induced activation of AMPK by decreasing the expression of the enzyme using siRNA inhibited the stimulation of 2-deoxyglucose uptake by the TZD. Conclusions/interpretation: We propose that troglitazone acutely increases glucose flux in muscle via an AMPK-mediated increase in glucose phosphorylation.

Keywords AMPK · Glucose uptake · GLUT4 · siRNA · Thiazolidinedione $\cdot$ Troglitazone

Abbreviations ACC: Acetyl CoA carboxylase - AICAR: Aminoimidazole carboxamide ribonucleotide - AMPK: AMP-activated protein kinase - 2-DGP: 2-Deoxyglucose-6phosphate - DNP: Dinitrophenol $\cdot$ HSQ: High-sucrose quench - KRPH: Krebs-Ringer phosphate HEPES - PFK2: Phosphofructokinase 2 - PI: Phosphatidylinositol - PKB: Protein kinase B - PPAR $\gamma$ : Peroxisome proliferatoractivated receptor $\gamma \cdot$ TZD: Thiazolidinedione

\section{Introduction}

The hypoglycaemic effect of thiazolidinediones (TZDs) involves activation of peroxisome proliferator-activated receptor $\gamma(\operatorname{PPAR} \gamma)$, a nuclear receptor and transcription factor important for adipocyte differentiation and lipid metabolism [1,2]. The beneficial metabolic effects of these drugs occur largely through the enhanced storage of lipids in adipose tissue, lowering NEFA availability to non-adi- 
pose tissues such as liver, skeletal muscle and beta cells. However, lipoatrophic (fatless) mice treated with TZDs exhibit improved insulin sensitivity in peripheral tissues $[3,4]$. This observation suggests that non-adipocyte targets for TZDs exist and that they participate in its metabolic effects. Consistent with this possibility, several studies also suggest a direct effect of TZDs on insulin sensitivity and glucose uptake in muscle cells, even though PPAR $\gamma$ expression in skeletal muscle is low [5, 6]. Recently, the role of muscle PPAR $\gamma$ in the improvement of muscle glucose homeostasis by TZDs was explored using mice with muscle-specific PPAR $\gamma$ gene deletion. Intriguingly, one study revealed that the action of TZDs does not rely on PPAR $\gamma$ expression in this tissue [7], whereas another suggested that PPAR $\gamma$ expression in muscle is relevant [8]. Thus, the mechanism by which TZDs affect muscle glucose metabolism remains elusive.

Troglitazone (also known as CS-045) was the first TZD approved for clinical use. Unfortunately, troglitazone had rare but serious side effects causing subacute irreversible liver injury and failure [9] and was recently removed from the market [10]. In studies geared to uncover the cause of the hepatotoxicity using human or rat hepatocyte cell lines, several mitochondrial abnormalities were observed including the collapse of the mitochondrial membrane potential $[11,12]$. In those studies, the effect of troglitazone on mitochondrial membrane potential was rapid (within an hour) and occurred at concentrations approximating those considered therapeutically active. Therefore, in hepatocytes, troglitazone may be a constant threat to the production of cellular ATP through oxidative metabolism.

Past studies from our laboratory have demonstrated a link between reduced mitochondrial ATP production, such as during hypoxia or after exposure to dinitrophenol and rotenone, and the stimulation of glucose uptake in L6 muscle cells in culture $[13,14]$. Others have demonstrated that lowering ATP levels in the clone 9 liver cell line through exposure to sodium azide also causes a rapid stimulation of glucose uptake [15]. All of these perturbations affect mitochondrial oxidative metabolism, transiently lowering cellular levels of ATP and placing a greater demand on glycolysis to supply essential levels of ATP to maintain cellular viability. The stimulation of glucose uptake would supply substrate for this increased demand on glycolysis. Troglitazone rapidly (in $30 \mathrm{~min}$ ) stimulates 2-deoxyglucose uptake into muscle cells [16], and hence we were intrigued by a potential connection between stimulation of glucose uptake by troglitazone and its effect on mitochondrial function.

Recent attention has been given to the potential role of AMP-activated protein kinase (AMPK) in the stimulation of glucose uptake in skeletal muscle during hypoxia or exercise [17-20]. AMPK is a cellular energy charge sensor that becomes activated in conditions of high cellular AMP: ATP ratio (e.g. low ATP) through its interaction with AMP and activation by upstream AMPK-kinase(s), such as the recently characterised LKB1 [21-23]. AMPK is a heterotrimeric kinase with $\alpha, \beta$, and $\gamma$ subunits. The $\alpha$ subunit has catalytic activity that is regulated by AMPK-kinase-me- diated phosphorylation of Thr172 on its activation loop and by interaction with the AMP-bound $\gamma$ subunit [24]. Once activated, AMPK may enhance mitochondrial ATP production largely by stimulating fatty acid oxidation through phosphorylation and inactivation of acetyl-CoA carboxylase (ACC) [24, 25]. In addition, AMPK activation may participate in the stimulation of glucose uptake in skeletal muscle in response to a number of stimuli expected to reduce cellular levels of ATP or phosphocreatine [26-28].

The present study explores the link between the acute effects of troglitazone on mitochondrial membrane potential, AMPK activity, and the stimulation of glucose uptake in muscle cells. We show that troglitazone rapidly depolarises mitochondrial membrane potential and increases glucose flux in cultured L6 muscle cells. The latter response requires input from AMPK, presumably activated by the mitochondrial depolarisation.

\section{Materials and methods}

Materials Troglitazone was a gift from H. Camp (Pfizer, Ann Arbor, MI, USA). Human insulin (Humulin R) was obtained from Eli Lilly Canada (Toronto, ON, Canada). Dinitrophenol (DNP), sodium azide $\left(\mathrm{NaN}_{3}\right)$, cytochalasin $\mathrm{B}$, and wortmannin were obtained from Sigma Chemical (St. Louis, MO, USA). Monoclonal antibody (9E10) to the myc-epitope was from Santa Cruz Biotechnology (Santa Cruz, CA, USA) and anti-IRS-1 antibody was from Upstate Biotechnology (Lake Placid, NY, USA). Anti-AMPK $\alpha 1 /$ $\alpha 2$, anti-phosphoT172-AMPK $\alpha$, anti-phosphoS79-ACC, and anti-phosphoS473- and phosphorT308-Akt antibodies were obtained from Cell Signalling (Beverly, MA, USA). Anti-AMPK $\alpha$ antibody used for immunoprecipitation and AMPK activity assay [29] was a kind gift from N. Ruderman (Boston University Medical Center, Boston, MA, USA). Anti-AMPK $\alpha 1$ was raised to the peptide CDFYLATSP PDSFLDDHHLTR; anti-AMPK $\alpha 2$ was a gift from L. Goodyear (Joslin Diabetes Center, Boston, MA, USA). JC-1 was purchased from Molecular Probes (Eugene, OR, USA). siRNA oligonucleotides were purchased from Dharmacon (Lafayette, CO, USA). 2-[ $\left.{ }^{3} \mathrm{H}\right]-$ deoxy-D-glucose and 3-O[methyl- $\left.{ }^{3} \mathrm{H}\right]-\mathrm{D}-$ glucose were from Perkin Elmer (Shelton, CT, USA). Disposable columns were from Pierce (Rockford IL, USA; catalogue no. 29920). DEAE-Sepharose Fast Flow was from Amersham Biosciences (Piscataway, NJ, USA). Trizol Reagent, Superscript II reverse transcriptase, oligo-dT and Taq DNA polymerase were purchased from Invitrogen Life Sciences (Carlsbad, CA, USA). All other reagents were of the highest analytical grade.

Cell culture and troglitazone treatment L6GLUT4myc myoblasts were differentiated into myotubes by growing them in $\alpha$-MEM supplemented with $2 \%$ fetal bovine serum as described previously [30]. At a seeding density of $2 \times$ $10^{4}$ cells $/ \mathrm{ml}(1$ and $2 \mathrm{ml}$ per well in 24 - or 12 -well plates, respectively) L6 cells fully differentiate into myotubes by day 7. Myotubes were deprived of serum for $3 \mathrm{~h}$ prior to all experimental manipulations. Troglitazone was prepared in 
DMSO as a 5-mg/ml stock solution, and diluted in $\alpha$-MEM before application to the cells. DMSO was added to control cells in all experiments to obtain the same final DMSO concentration as in troglitazone-treated conditions.

Assessment of mitochondrial membrane potential $(\Delta \psi)$ using the fluorescent indicator JC-1 JC-1 (5,5',6,6'-tetracholoro-1,1',3,3'-tetraethylbenzimidazolylcarbocyanine iodide) is a positively charged fluorescent compound which is taken up by mitochondria proportionally to the inner mitochondrial membrane potential [31]. When a critical concentration is reached, JC-1 monomers form J-aggregates, altering the fluorescence properties of the compound. Thus, the ratio of red (J-aggregate)/green (monomeric JC-1) emission is directly proportional to the mitochondrial membrane potential $(\Delta \psi)$. To assess the effect of troglitazone on $\Delta \psi$, L6GLUT4myc myotubes were grown on glass coverslips. Following serum deprivation, cells were rinsed and incubated in Krebs-Ringer phosphate HEPES (KRPH) buffer (to which $5 \mathrm{mmol} / \mathrm{l}$ glucose were added), containing $1 \mu \mathrm{g} /$ $\mathrm{ml} \mathrm{JC}-1$ for $20 \mathrm{~min}$ at $37^{\circ} \mathrm{C}$. Coverslips were then rinsed five times with KRPH and analysed by live-cell confocal microscopy (Zeiss LSM 510 laser scanning confocal microscope) during which coverslips were maintained at $37^{\circ} \mathrm{C}$ using a specimen stage heater. To view J-aggregates, excitation and emission were recorded at $543 />560 \mathrm{~nm}$; for monomeric JC-1 they were recorded at 488/505-530 nm. A pseudocolour value was assigned to the acquisition of the $\mathrm{red} /$ green ratio and exported to NIH Image-J software. For each coverslip, three images of each condition were analysed, and the intensity of the red/green fluorescence ratio signal from 20 mitochondria in each image was determined.

Detection of Akt, AMPK and ACC phosphorylation L6GLUT4myc myotubes grown in six-well plates were incubated with either $5 \mu \mathrm{g} / \mathrm{ml}$ troglitazone or $100 \mathrm{nmol} / \mathrm{l}$ insulin for $10 \mathrm{~min}$. The cells were lysed with $300 \mu \mathrm{l}$ of $2 \times$ Laemmli sample buffer supplemented with $1 \mathrm{mmol} / 1 \mathrm{DTT}$, $1 \mathrm{mmol} / 1 \mathrm{Na}_{3} \mathrm{VO}_{4}, 100 \mathrm{nmol} / \mathrm{l}$ okadaic acid, protease inhibitors ( $1 \mathrm{mmol} / \mathrm{l}$ benzamidine, $10 \mu \mathrm{mol} / 1 \mathrm{E}-64,1 \mu \mathrm{mol} / \mathrm{l}$ leupeptin, $1 \mu \mathrm{mol} / 1$ pepstatin $\mathrm{A}, 0.2 \mathrm{mmol} / 1 \mathrm{PMSF})$ and $7.5 \% \beta$-mercaptoethanol. The lysates were transferred to Eppendorf tubes, vortexed for $1 \mathrm{~min}$, passed five times through a 25-gauge syringe and heated for $15 \mathrm{~min}$ at $65^{\circ} \mathrm{C}$. Samples were centrifuged for $5 \mathrm{~min}(10,000 \mathrm{~g})$ then $40 \mu \mathrm{l}$ (50 $\mathrm{\mu g}$ protein) of the supernatant were resolved by $10 \%$ SDS-PAGE, electrotransferred onto PVDF membranes and immunoblotted for phosphoT308-Akt (1:1,000 dilution), phosphoS473-Akt $(1: 1,000)$, phosphoS79-ACC $(1: 1,000)$, phosphoT172-AMPK $\alpha(1: 750)$, or total AMPK $\alpha(1: 1,000)$.

In vitro PI 3-kinase and AMPK activity assay Phosphatidylinositol (PI) 3-kinase activity associated with IRS-1 immunoprecipitates was measured using phosphatidylinositol and ${ }^{32} \mathrm{P}-\mathrm{ATP}$ as substrates [32]. AMPK activity was measured after immunoprecipitation using recombinant SAMS peptide and ${ }^{32} \mathrm{P}-\mathrm{ATP}$, as described earlier [33].
Determination of 2-deoxy- ${ }^{3} \mathrm{H}$-D-glucose and 3-O-methyl${ }^{3} H$-D-glucose uptake 2-Deoxyglucose uptake was measured as described earlier [34]. Briefly, after $30 \mathrm{~min}$ of stimulation with insulin or troglitazone, cells were washed three times with HBS buffer $(140 \mathrm{mmol} / 1 \mathrm{NaCl}, 20 \mathrm{mmol} / 1$ HEPES pH 7.4, $5 \mathrm{mmol} / 1 \mathrm{KCl}, 2.5 \mathrm{mmol} / 1 \mathrm{MgSO}_{4}, 1 \mathrm{mmol} /$ $1 \mathrm{CaCl}_{2}$ ). 2-Deoxyglucose uptake was measured for $5 \mathrm{~min}$ at room temperature by incubating cells with HBS containing $10 \mu \mathrm{mol} / 12$-deoxyglucose, $37 \mathrm{kBq} / \mathrm{ml}$, and the reaction was stopped by three washes with ice-cold $0.9 \% \mathrm{NaCl}(\mathrm{w} / \mathrm{v})$. A similar protocol was used for 3-O-methylglucose uptake, with the following exceptions: 3-O-methylglucose uptake was measured for $30 \mathrm{~s}$ using HBS supplemented with 10 $\mu \mathrm{mol} / 13-O$-methylglucose, $185 \mathrm{kBq} / \mathrm{ml}$, and the reaction was stopped by adding ice-cold $0.9 \% \mathrm{NaCl}(\mathrm{w} / \mathrm{v})$ supplemented with $20 \mu \mathrm{mol} / \mathrm{l}$ cytochalasin $\mathrm{B}$ and $2 \mathrm{mmol} / \mathrm{l}$ $\mathrm{HgCl}_{2}$.

Separation of 2-deoxyglucose and 2-deoxyglucose-6-phosphate Separation of cell-associated 2-deoxyglucose from 2deoxyglucose-6-phosphate (2-DGP) was performed as previously described [35]. Briefly, 2-deoxyglucose uptake was measured as described above but with $111 \mathrm{kBq} / \mathrm{ml}$ of ${ }^{3} \mathrm{H}$-2-deoxyglucose, and the reaction was stopped on ice using ice-cold saline supplemented with $20 \mu \mathrm{mol} / 1$ cytochalasin $\mathrm{B}$ and $2 \mathrm{mmol} / 1 \mathrm{HgCl}_{2}$. Cells (one well of a six-well plate per condition) were extracted overnight in $50 \%$ ethanol at $4^{\circ} \mathrm{C}$ and then scraped, collected and centrifuged for $15 \mathrm{~min}$ at $10,000 \mathrm{~g}$. The supernatant was loaded onto small columns containing DEAE-Sepharose $(0.5 \mathrm{ml}$ bed volume), prepared following the manufacturer's instructions. The flow-through was reloaded twice to ensure maximal binding of 2-DGP to the DEAE-Sepharose. Free 2-deoxyglucose was recovered in the final flow-through and in the following three $2-\mathrm{ml}$ washes with $50 \mathrm{mmol} / 1$ glucose solution in water. In separate experiments, recovery in these fractions was more than $96 \%$ of the counts when only free 2-deoxyglucose was loaded (results not shown). Elution of 2-DGP was done by three 2-ml washes with $200 \mathrm{mmol} / 1$ $\mathrm{HCl}$ (more than $99 \%$ of the counts of this fraction were recovered in the first fraction). The counts obtained after addition of $20 \mu \mathrm{mol} / 1$ cytochalasin B to the transport solution were subtracted from their respective fractions, to account for transport-independent cell-associated radioactivity.

Immunodetection of cell surface GLUT4myc or GLUT1myc Detection of surface GLUT4myc or GLUT1myc was performed on intact myotubes as previously described [30]. Briefly, L6-GLUT4myc myotubes or L6-GLUT1myc myotubes grown in 24-well tissue culture plates were treated with vehicle $(0.1 \%$ DMSO), troglitazone $(5 \mu \mathrm{g} / \mathrm{ml})$ or insulin $(100 \mathrm{nmol} / \mathrm{l})$ for $30 \mathrm{~min}$. Cells were then placed on ice, rinsed twice with ice-cold $\mathrm{PBS}$, blocked with 5\% goat serum in PBS for $15 \mathrm{~min}$, and reacted with the anti-myc antibody 9E10 (2 $\mu \mathrm{g} / \mathrm{ml}$ in PBS containing 3\% goat serum) at $4^{\circ} \mathrm{C}$ for $1 \mathrm{~h}$. After four washes with ice-cold PBS, cells were fixed with $3 \%(\mathrm{v} / \mathrm{v})$ paraformaldehyde in $\mathrm{PBS}$ at $4^{\circ} \mathrm{C}$ for $10 \mathrm{~min}$, followed by quenching with $100 \mathrm{mmol} / 1$ glycine in PBS for $10 \mathrm{~min}$ and incubation with secondary antibody 
(HRP-conjugated donkey anti-mouse IgG, 1:1,000 in PBS containing $3 \%$ goat serum) at $4^{\circ} \mathrm{C}$ for $1 \mathrm{~h}$. Cell plates were washed six times with PBS, then $1 \mathrm{ml} / \mathrm{well}$ of $0.4-\mathrm{mg} / \mathrm{ml}$ OPD reagent (HRP substrate) was added at room temperature for 20-30 min. The reaction was stopped by adding $0.25 \mathrm{ml}$ of $3 \mathrm{NH}_{4} \mathrm{Cl}$, and the optical absorbance was measured at $492 \mathrm{~nm}$. Background absorbance values were obtained in all experiments in several untreated cell wells by omitting the primary (anti-myc) antibody incubation period during the assay. Absorbance values in these wells were subtracted from the value achieved with anti-myc.

Detection of AMPK $\alpha 1$ and $\alpha 2$ isoforms L6GLUT4myc cells were scraped from one $10-\mathrm{cm}$ dish in PBS, collected, and centrifuged for $15 \mathrm{~min}$ at $10,000 \mathrm{~g}$. The supernatant was removed and the pellet quickly frozen in liquid nitrogen for storage. For Western blotting, the pellets were lysed in a $1 \%(\mathrm{v} / \mathrm{v})$ triton-X100 buffer (Tris-Cl $20 \mathrm{mmol} / \mathrm{l}$, $\mathrm{NaCl} 50 \mathrm{mmol} / \mathrm{l}, \mathrm{NaF} 50 \mathrm{mmol} / \mathrm{l}$, NaPPi $5 \mathrm{mmol} / \mathrm{l}$ ) and sucrose $250 \mathrm{mmol} / \mathrm{l}$ (containing protease inhibitors and DTT) for $15 \mathrm{~min}$ on ice and centrifuged for $10 \mathrm{~min}$ at $4^{\circ} \mathrm{C}$. The supernatant was removed to a new tube and highsucrose quench (HSQ; containing bromphenol blue, DTT and SDS in 50\% sucrose) was added at a ratio of 1:4 (HSQ/ lysate). Eighteen micrograms of protein were resolved by $10 \%$ SDS-PAGE then electrotransferred onto PVDF membranes and immunoblotted for AMPK $\alpha 1$ or $\alpha 2$.

Design of siRNA and transfection of myotubes Three siRNA sequences for each of the two $\alpha$ isoforms of rat AMPK were screened for their capacity to decrease total AMPK $\alpha$ protein levels in L6 myotubes. The highest efficiency of gene silencing was achieved with the following sequences derived from the $\alpha 1$ and $\alpha 2$, respectively: GCA UAU GCU GCA GGU AGA UdTdT (nucleotides 738756, accession number NM019142) and CGU CAU UGA UGA UGA GGC UdTdT (nucleotides 865-883, accession number NM023991). The combination of both siRNAs proved to be most effective in reducing AMPK $\alpha 1 / \alpha 2$ expression, suggesting that both subunits are expressed in L6 cells. An unrelated siRNA purchased from Dharmacon (catalogue no. D-001206-10) was used as the control in all experiments. The transfection protocol was optimised in preliminary experiments using fluorophore-conjugated siRNA, which revealed high ( $>90 \%$ ) transfection efficiency (results not shown). In all experiments confluent monolayers of L6 cells (seeded and grown as described in the cell culture section) were transfected 5 days after seeding. siRNA ( $200 \mathrm{nmol} / 1$ of each oligonucleotide sequence) was suspended in serum- and antibiotic-free media, prepared for transfection with Oligofectamine (Invitrogen, Carlsbad, CA, USA), following the instructions of the manufacturer, and applied on the cells for 3-4 h. The serum concentration was then adjusted to $2 \%$ by adding a half volume of antibiotic-free medium supplemented with $6 \%$ serum and incubated an additional $20 \mathrm{~h}$. Afterwards, one volume of media supplemented with antibiotics and $2 \%$ serum was added to the cells for an additional $24 \mathrm{~h}$. Therefore, the siRNA nucleotides remained on the cells for $48 \mathrm{~h}$. Impor- tantly, fusion of myoblasts into myotubes was normal under all treatment conditions and protein recovery in the siRNAtreated cells was unaffected. Before experimentation, cells were serum starved for $3 \mathrm{~h}$ before being used to prepare cell lysates (from 12-well plates) or for 2-deoxyglucose uptake (in 24-well plates).

Statistical analysis Statistical analysis was performed using either ANOVA (Fisher's multiple comparisons test) or paired Student's $t$-test. A $p$ value of less than 0.05 was considered significant as indicated.

\section{Results}

Acute mitochondrial membrane depolarisation by troglitazone in muscle cells The mitochondrial membrane potential was assessed using the dye JC-1, a lipophilic fluorophore that forms $\mathrm{J}$-aggregates in proportion to its intramitochondrial concentration, dictated by the mitochondrial membrane potential. L6GLUT4myc myotubes were preincubated for $20 \mathrm{~min}$ with $1 \mu \mathrm{g} / \mathrm{ml} \mathrm{JC}-1$, rinsed thoroughly and treated with $5 \mu \mathrm{g} / \mathrm{ml}(11 \mu \mathrm{mol} / \mathrm{l})$ troglitazone for $10 \mathrm{~min}$. Figure 1 presents typical images of the JC-1 fluorescence. The top row in each grouping shows merged images of the red and green signal of the dye. The bottom row in each grouping represents the ratio of red/green fluorescence, corresponding to JC-1 in J-aggregate vs monomeric form. The results obtained clearly show that $10 \mathrm{~min}$ of incubation with troglitazone reduced JC-1 dye accumulation and decreased J-aggregate formation in the mitochondria of L6GLUT4myc myotubes, consistent with mitochondrial membrane depolarisation. In fact, following treatment with troglitazone, the number of mitochondria still exhibiting a discernable red/green ratio signal was markedly decreased. A similar effect was observed when cells were incubated for $10 \mathrm{~min}$ with either $10 \mathrm{mmol} / 1$ sodium azide or 0.5 $\mathrm{mmol} / \mathrm{l} \mathrm{DNP}$. These findings suggest that both inhibition of the mitochondrial electron transport chain (with $\mathrm{NaN}_{3}$ ) and mitochondrial membrane uncoupling (with DNP) cause mitochondrial membrane depolarisation, consistent with a previous report [36]. In contrast, insulin stimulation (100 nmol/1, $10 \mathrm{~min}$ ) did not cause mitochondrial membrane depolarisation.

Troglitazone acutely activates AMPK in muscle cells Maintaining mitochondrial membrane potential is required for ATP production [37-39]. By depolarising mitochondria, troglitazone may have provoked a rise in the cellular AMP/ ATP ratio. This is likely, since both rosiglitazone and pioglitazone elevate AMP levels and activate AMPK in $\mathrm{H}-2 \mathrm{~K}^{\mathrm{b}}$ muscle cells and rat liver [40, 41]. Consistent with this possibility, incubation of L6GLUT4myc myotubes with troglitazone for 5 or 10 min significantly increased AMPK activity measured by an in vitro kinase activity assay using SAMS peptide as a substrate (Fig. 2a). A similar level of AMPK activation was observed with $0.5 \mathrm{mmol} / 1 \mathrm{DNP}$ (Fig. 2a), a mitochondrial uncoupler previously shown to activate AMPK [27, 33]. Like DNP, troglitazone also in- 

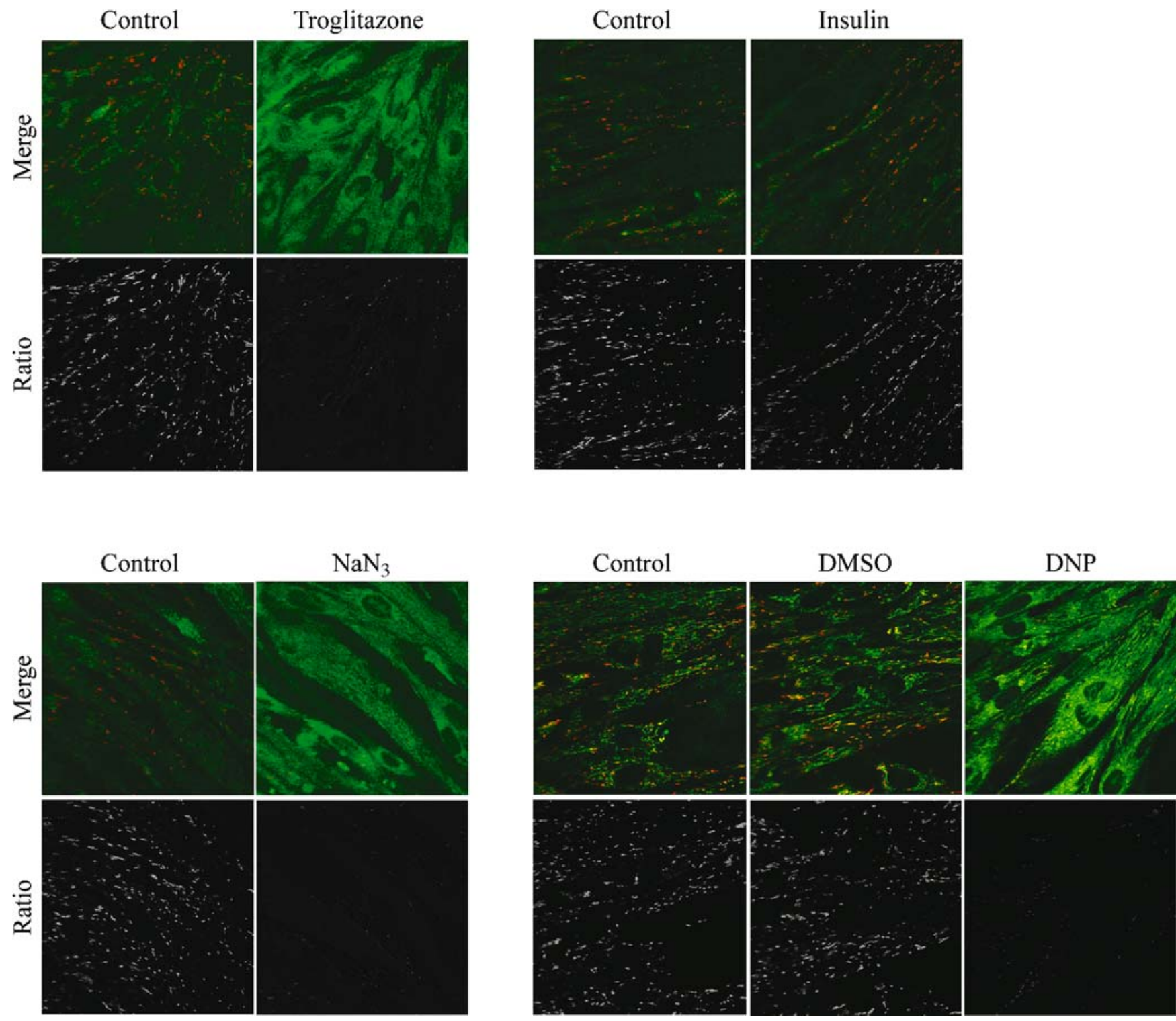

Fig. 1 Troglitazone depolarises mitochondrial membranes. L6GLUT4 myc myotubes grown on glass coverslips were serum starved for $3 \mathrm{~h}$ and then preincubated for $20 \mathrm{~min}$ with $1 \mu \mathrm{g} / \mathrm{ml} \mathrm{JC}-1$. After rinsing, cells were subjected to live-cell confocal microscopy as described in Materials and methods. After acquisition of the basal image, $5 \mu \mathrm{g} / \mathrm{ml}$ (11 $\mu \mathrm{mol} / \mathrm{l})$ troglitazone, $100 \mathrm{nmol} / \mathrm{l}$ insulin, $0.1 \%$ DMSO, 10 $\mathrm{mmol} / 1$ sodium azide $\left(\mathrm{NaN}_{3}\right)$ or $0.5 \mathrm{mmol} / \mathrm{l} \mathrm{DNP}$ were added.
Images were taken before and 10 min after addition of the different compounds as indicated. Shown are representative confocal images for each condition. The upper panel shows a merged image of the red and green fluorescence indicating the J-aggregate and monomeric forms of the JC-1 dye respectively. The lower panel shows the composite ratio of the red/green fluorescence intensity, presented here in grey scale creased AMPK $\alpha$ phosphorylation on T172 (Fig. 2b) as well as the phosphorylation on S79 of ACC, a substrate of AMPK (Fig. 2c). Hence, troglitazone rapidly activated AMPK in muscle cells, consistent with the physiological response to an acute increase in the cellular AMP:ATP ratio.

Troglitazone acutely stimulates glucose phosphorylation Several observations implicate AMPK in the stimulation of glucose uptake and utilisation by skeletal muscle induced by contraction, hypoxia or exercise $[27,42,43]$. To assess whether troglitazone-stimulated AMPK activity in L6GLUT4myc muscle cells is associated with a similar physiological outcome, we measured the effect of troglita- zone treatment on 2-deoxyglucose uptake. L6GLUT4myc myotubes incubated for $30 \mathrm{~min}$ with $5 \mu \mathrm{g} / \mathrm{ml}$ troglitazone displayed a significant increase in 2-deoxyglucose accumulation measured in the $5 \mathrm{~min}$ subsequent to treatment with the drug (Fig. 3a). Similar results were obtained with wild-type L6 myotubes (data not shown). Whereas 2-deoxyglucose accumulation provides a composite measure of transport through glucose transporters and phosphorylation of this glucose analogue by hexokinase, 3-O-methylglucose uptake reflects only the transport step since this glucose analogue cannot be phosphorylated by hexokinase. Intriguingly, troglitazone had no significant effect on 3-Omethylglucose transport (Fig. 3b). In contrast, insulin stim- 
a

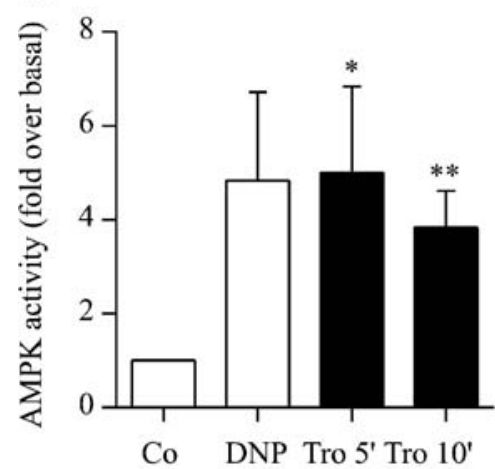

b

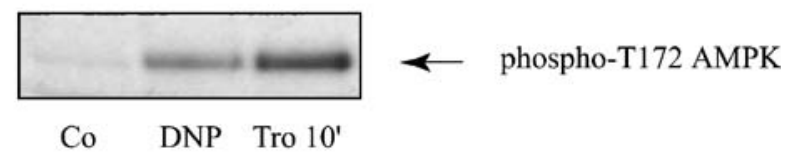

C

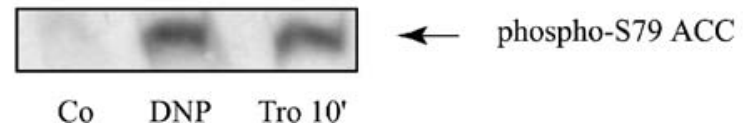

Fig. 2 Troglitazone acutely activates AMPK in L6GLUT4myc myotubes. a L6 GLUT4myc myotubes were treated for 5 or $10 \mathrm{~min}$ with $5 \mu \mathrm{g} / \mathrm{ml}$ troglitazone or for 5 min with $0.5 \mathrm{mmol} / 1$ DNP. AMPK was immunoprecipitated and kinase activity determined by an in vitro kinase assay using ${ }^{32} \mathrm{P}$ and the SAMS peptide as substrate. Results are the means $\pm \mathrm{SE}$ of three to four experiments. $\mathbf{b}$, c Total cell lysates were prepared from L6GLUT4myc muscle cells that were treated with $5 \mu \mathrm{g} / \mathrm{ml}$ troglitazone or $0.5 \mathrm{mmol} / \mathrm{l} \mathrm{DNP}$ for $10 \mathrm{~min}$. Lysates $(50 \mu \mathrm{g})$ were resolved by $10 \%$ SDS-PAGE and immunoblotted with anti-phosphoT172-AMPK antibody or antiphosphoS79-ACC antibody. A representative immunoblot of three independent experiments is shown. ${ }^{*} p<0.05$ and ${ }^{*} p<0.01$ vs control. Co Control, Tro troglitazone

ulated 3-O-methylglucose and 2-deoxyglucose uptake to a similar degree (Fig. 3b). Consistent with this minimal increase in the rate of glucose transport, troglitazone did not significantly increase the abundance of GLUT4myc at the cell surface. In contrast, and as expected, insulin stimulation induced a two-fold increase in surface GLUT4myc (Fig. 3c). To examine a possible contribution of GLUT1 translocation to the effect of troglitazone, we determined cell surface myc exposure in L6GLUT1myc myotubes, a cell line that stably overexpresses GLUT1 bearing an extracellular myc-epitope. As shown in Fig. 3d, troglitazone did not increase cell surface GLUT1myc significantly, yet it caused an increase in 2-deoxyglucose accumulation of 1.9 \pm 0.1 -fold $(p<0.001$; data not shown). Hence, troglitazone can acutely stimulate 2-deoxyglucose uptake without a parallel increase in the abundance of GLUT1 or GLUT4 in the plasma membrane, and without enhancing glucose transport through GLUTs (as detected with 3-O-methylglucose).

To verify that troglitazone increased 2-deoxyglucose accumulation primarily by enhancing hexose phosphorylation, we determined the ratio of free 2-deoxyglucose/2DGP. The 2-deoxyglucose uptake assay was performed as before, with the exception of preventing efflux of free 2deoxyglucose at the end of the assay using cytochalasin B and $\mathrm{HgCl}_{2}$. Cells were then extracted and subjected to anion exchange chromatography. While troglitazone only marginally increased free 2-deoxyglucose in the cells (Fig. 4a), it increased 2-DGP more than two-fold (Fig. 4b). In contrast, insulin similarly increased 2-deoxyglucose and 2-DGP in the cells to the same extent. This finding suggests that the discrepancy between the effects of troglitazone on 2-deoxyglucose and on 3-O-methylglucose uptake (Fig. 3a and $\mathrm{b}$, respectively), cannot be attributed to differences in the $K_{\mathrm{m}}$ for uptake of each glucose analogue. This is consistent with reports demonstrating that the $K_{\mathrm{m}}$ of 2-deoxyglucose and 3-O-methylglucose for GLUT4 are essentially identical when GLUT4 is expressed in Xenopus oocytes [44-46].

Acute regulation of hexokinase is largely achieved by allosteric modulation that cannot be discernible by enzyme activity assays in cell lysates, since the endogenous concentration of allosteric regulators is lost upon cell lysis. Thus, the ratio of 2-DGP/free 2-deoxyglucose (product and substrate of hexokinase, respectively) is frequently used as a measure of 'authentic' hexokinase activity in the cells. Consistent with troglitazone-induced increase in hexokinase flux, a $1.8 \pm 0.5$-fold $(p<0.05)$ increase in 2 -DGP/free 2-deoxyglucose ratio was observed in cells treated with troglitazone (Fig. 4c). Insulin also increased hexokinase flux, though its effect was smaller in magnitude than that of troglitazone. These data suggest that, in contrast to insulin, troglitazone largely increases 2-deoxyglucose accumulation by enhancing hexose phosphorylation, with a small contribution from enhanced hexose transport. In aggregate, the data presented so far demonstrate that troglitazone acutely reduces mitochondrial membrane potential, activates AMPK, and increases glucose utilisation by hexokinase.

Troglitazone-induced glucose flux does not involve activation of the PI 3-kinase-Akt/PKB signalling pathway Insulin stimulation of glucose uptake requires activation of a signalling pathway involving PI 3-kinase and Akt. In addition, Akt/protein kinase $\mathrm{B}$ (PKB) is involved in multiple conditions in which mitochondrial function is altered, presumably mediating an anti-apoptotic signal [47]. We therefore first assessed whether troglitazone activated the PI 3-kinase-Akt/PKB pathway by measuring association of PI 3-kinase with IRS1. As expected, insulin induced IRS1associated PI 3-kinase activity, detected by an in vitro kinase assay. In contrast, troglitazone treatment had no significant effect vs vehicle-treated controls (Fig. 5a). In addition, troglitazone did not increase phosphorylation of Akt/PKB on either T308 or S473, which occurred robustly following insulin stimulation (Fig. 5b). The PI 3-kinase inhibitor wortmannin was used to further determine any possible contribution of PI 3-kinase to the troglitazone response of 2-deoxyglucose uptake. At $25 \mathrm{nmol} / 1$, wortmannin had no significant effect on basal 2-deoxyglucose uptake. Treatment of the cells with $25 \mathrm{nmol} / 1$ wortmannin $20 \mathrm{~min}$ prior to and during incubation with troglitazone had no effect on the stimulation of 2-deoxyglucose uptake by troglitazone, while almost completely abolishing the effect of insulin (Fig. 5c). Collectively, these results imply that insulin and troglitazone stimulate 2-deoxyglucose uptake 
Fig. 3 Troglitazone acutely stimulates 2-deoxyglucose uptake without inducing 3-Omethylglucose uptake, or GLUT4 or GLUT1 translocation. a L6GLUT4myc myotubes were incubated for $30 \mathrm{~min}$ without or with insulin or with $5 \mu \mathrm{g} / \mathrm{ml}$ troglitazone. 2-Deoxyglucose was determined as described in Materials and methods. Results are the means \pm $\mathrm{SE}$ of five independent experiments. b After troglitazone or insulin stimulation, 3-Omethylglucose uptake was measured during a 30 -s assay as described in Materials and methods. Results are the means \pm $\mathrm{SE}$ of five independent experiments. c, d Cells were treated as above, after which surface GLUT4myc content in L6GLUT4myc myotubes or surface GLUT1myc content in L6GLUT1myc myotubes was detected in nonpermeabilised cells as described in Materials and methods. Results are presented as fold over basal, and are the means $\pm \mathrm{SE}$ of three to five independent experiments. $* * p<0.01$ and $* * * p<0.001$ vs control. Co Control, Tro troglitazone
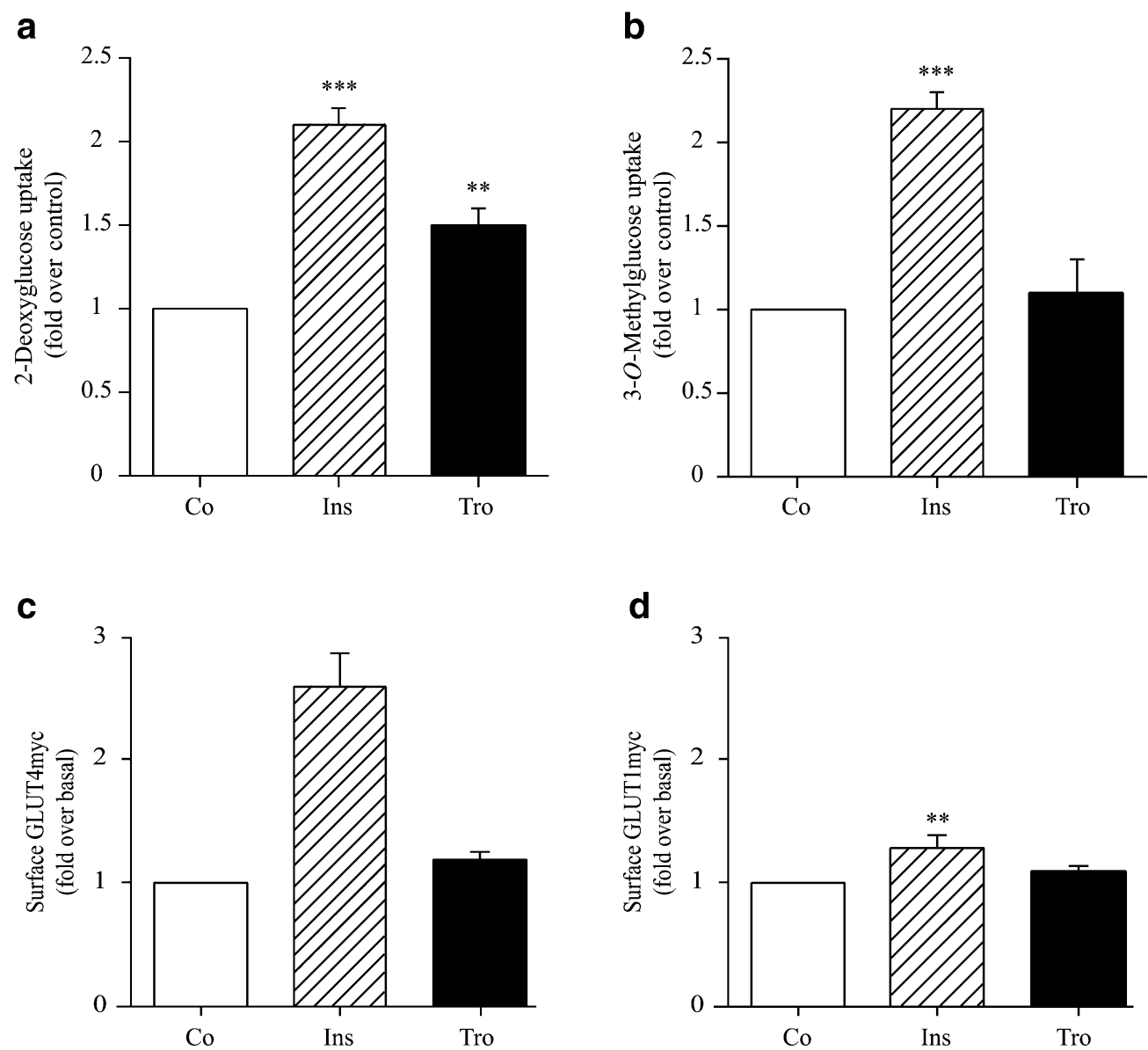

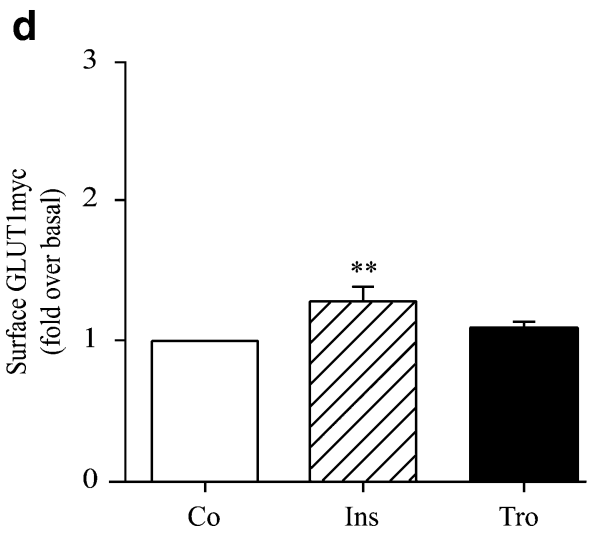

via different signalling mechanisms and that troglitazone acutely stimulates glucose utilisation (i.e. the phosphorylation of glucose) without significantly involving a PI 3kinase-Akt/PKB pathway.

AMPK activation by troglitazone is causatively linked to the stimulation of glucose flux To establish a causative role for AMPK in troglitazone-induced glucose utilisation, AMPK $\alpha$ protein content was lowered using an RNA silencing approach. Both $\alpha 1$ and $\alpha 2$ isoforms of AMPK are readily discernible in L6GLUT4myc myotubes using isoform-specific antibodies (Fig. 6a). Therefore, a combination of two siRNA oligonucleotide sequences derived from the two isoforms of the $\alpha$ subunit were used. The AMPK $\alpha 1$ / $\alpha 2$-siRNA oligonucleotides reduced the total expression of the $\alpha$ subunits of AMPK by $55 \pm 6 \%(p<0.001$, ANOVA) compared with transfection with equal concentration of an unrelated siRNA sequence (Fig. 6b, c). This level of reduction in AMPK $\alpha$ protein content was associated with a $36 \pm 8 \%$ decrease ( $p<0.01$, paired $t$-test vs unrelated siRNA) in troglitazone-mediated AMPK $\alpha$ phosphorylation on Thr172 (average of $n=4$ such as that illustrated in Fig. 6b, c). To demonstrate the specificity of the AMPK siRNA action, insulin-stimulated Akt phosphorylation was determined under the same four conditions and was not affected by any of the treatments compared with untransfected controls (results not shown). Both unrelated siRNA and AMPK $\alpha 1 /$ $\alpha 2$-siRNA induced a mild but reproducible increase in basal 2-deoxyglucose uptake. However, the net increase in 2-deoxyglucose uptake above basal in response to troglitazone was diminished by $57 \pm 8 \%$ in AMPK $\alpha 1 / \alpha 2$ siRNA-transfected cells $(p<0.05$, paired $t$-test $)$, while the net increase in response to insulin was not affected by AMPK $\alpha 1 / \alpha 2$-siRNA (Fig. 6d). Taken together, these findings demonstrate that AMPK has major input into the stimulation of glucose utilisation by troglitazone.

To explore whether the AMPK $\alpha 1 / \alpha 2$-siRNA might have prevented the mitochondrial depolarisation caused by troglitazone, we measured the fluorescence ratio of the JC-1 dye in myotubes pretreated with the siRNA mixture. As seen in Fig. 7, troglitazone caused its expected reduction in red:green fluorescence ratio and this action was not prevented upon reducing AMPK expression by $47 \%$. Hence, the most likely series of events is that troglitazone rapidly causes mitochondrial depolarisation which in turn activates AMPK, and this activation increases hexose phosphorylation.

\section{Discussion}

There is strong evidence to suggest that adipose tissue PPAR $\gamma$ does not mediate the entire range of therapeutic and adverse effects attributed to TZDs [48]. Instead, these agents appear to target organs such as the liver and skeletal muscle, where they elicit metabolic and cytotoxic responses. Recent 
Fig. 4 Troglitazone acutely stimulates 2-deoxyglucose phosphorylation. a, b L6GLUT4myc myotubes were treated for $30 \mathrm{~min}$ without or with insulin or with $5 \mu \mathrm{g} / \mathrm{ml}$ troglitazone, and levels of free 2-deoxyglucose (2-DG) (a) and 2-DGP (b) were determined as described in Materials and methods. Results are presented as fold over basal, and are the means \pm SE of four independent experiments. c The ratio of 2-DGP:2-DG for each condition was calculated. $* p<0.05$, $* * p<0.01$ and $* * * p<0.001$ vs control. Co Control, Tro troglitazone a
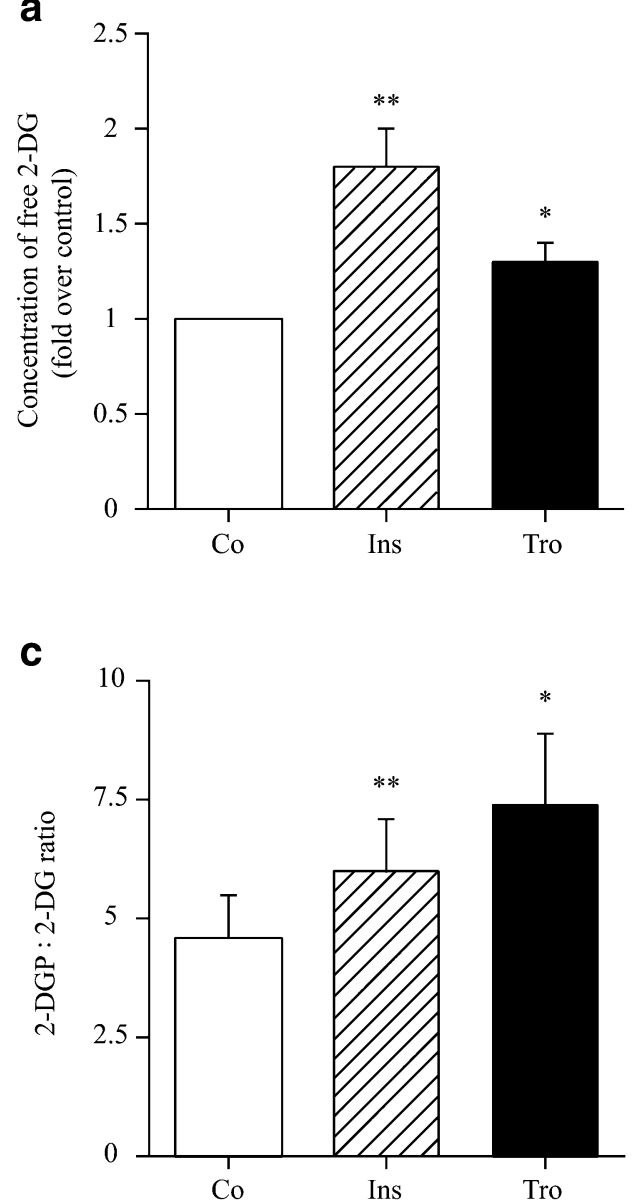

b

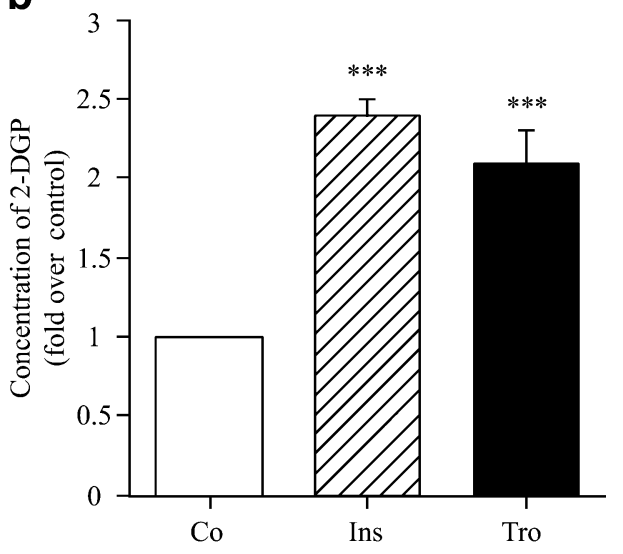

reports have shown that TZDs affect mitochondrial function and lower ATP production in human hepatocytes and $\mathrm{H}-$ $2 \mathrm{~K}^{\mathrm{b}}$ muscle cells $[11,12,40,41]$. Here, we extend these results by demonstrating that troglitazone induces acute mitochondrial membrane depolarisation, activates AMPK and accelerates glucose flux in muscle cells. Moreover, using specific siRNA, we directly implicate AMPK activation in mediating the stimulation of glucose flux by troglitazone.

Mitochondrial membrane depolarisation and acute activation of AMPK by troglitazone Mitochondrial membrane depolarisation is expected to lower cellular ATP levels, since mitochondrial energy production depends on the electrical and proton gradients across the inner mitochondrial membrane [37]. In principle, the troglitazone-induced mitochondrial membrane depolarisation (Fig. 1 and [49]) could arise either from an acute uncoupling of the respiratory chain from ATP synthase, or from inhibition of the electron transfer along the respiratory chain. Although the effect of troglitazone on the mitochondria was comparable in magnitude and time course to that induced by DNP (Fig. 1), troglitazone is unlikely to act as an uncoupler since it acutely reduces $\mathrm{CO}_{2}$ production from glucose or palmitate in isolated skeletal muscle [50]. Mitochondrial uncouplers accelerate, rather than inhibit, $\mathrm{CO}_{2}$ production from these substrates. The possibility that troglitazone inhibits the ATP synthase (complex V) is also unlikely since the ATP synthase inhibitor oligomycin does not reduce mitochondrial membrane potential [49]. However, the capacity of TZDs to interact with a specific mitochondrial membrane protein has been recently demonstrated [51]. Therefore, we entertain the possibility that, like the complex IV inhibitor $\mathrm{NaN}_{3}$, troglitazone acutely interacts with components of the respiratory chain upstream of the ATP synthase, decreasing mitochondrial ATP production. This effect of troglitazone may be shared by other clinically relevant thiazolidinediones, since rosiglitazone and pioglitazone inhibit respiratory complex I and reduce oxygen consumption in skeletal muscle [52] and elevate AMP levels in $\mathrm{H}-2 \mathrm{~K}^{\mathrm{b}}$ muscle cells and rat liver [40, 41]. Consequently, AMPK is activated via phosphorylation on $\mathrm{T} 172$ by an upstream AMPK kinase, potentially LKB-1, and by allosteric activation by the elevated AMP/ATP ratio and/or the creatine/ phosphocreatine ratio $[21-23,53]$.

AMPK activation mediates troglitazone-stimulated hexose flux in muscle cells Physiological stimuli such as muscle contraction and manipulations such as hypoxia or inhibition of mitochondrial function elevate AMPK activity and glucose uptake. Likewise, the cell permeant AMPK activator, aminoimidazole carboxamide ribonucleotide (AICAR), in- 


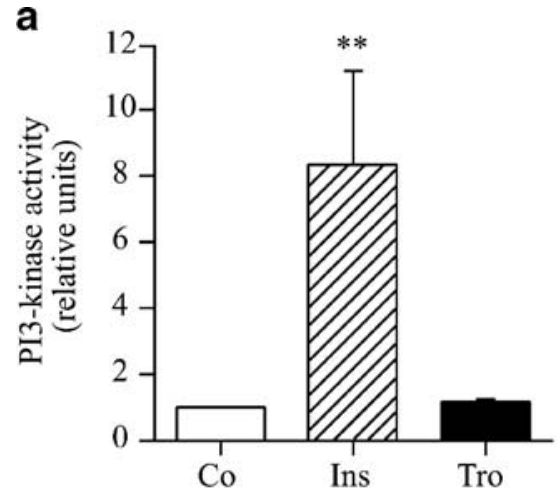

b
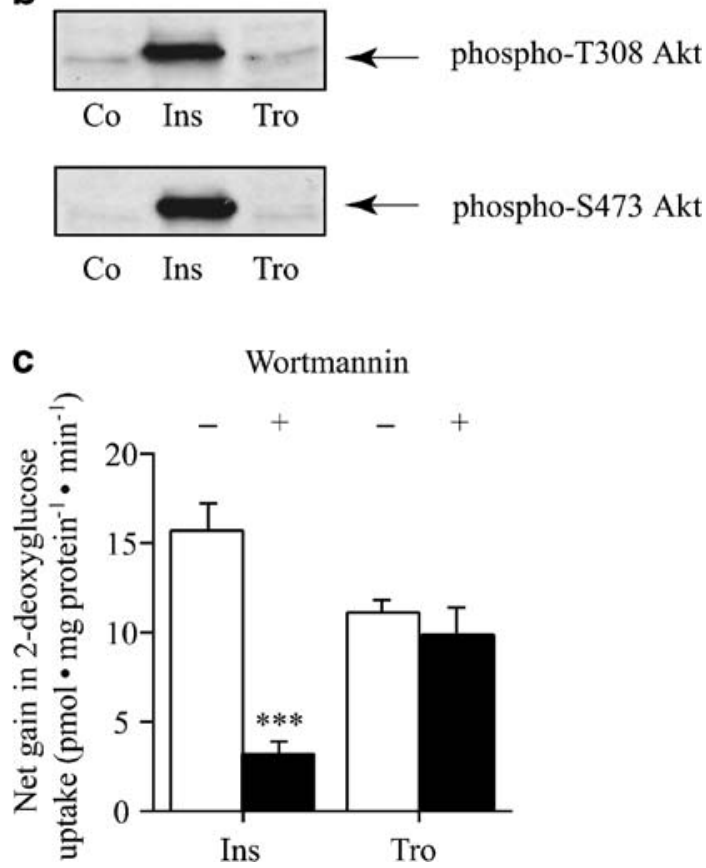

Fig. 5 Troglitazone and insulin-mediated stimulation of 2-deoxyglucose occurs through distinct signalling and cellular mechanisms. a L6GLUT4myc myotubes were treated for $10 \mathrm{~min}$ with or without $5 \mu \mathrm{g} / \mathrm{ml}$ troglitazone or $100 \mathrm{nmol} / 1$ insulin. IRS-1-associated PI3kinase activity was then determined using an in vitro kinase assay towards PI. Results are expressed in relative units and represent the means \pm SE of three independent experiments. $* * p<0.01$ vs control. b Total cell lysates were prepared from L6GLUT4myc muscle cells that were treated with $5 \mu \mathrm{g} / \mathrm{ml}$ troglitazone or $100 \mathrm{nmol} / 1$ insulin for $10 \mathrm{~min}$. Lysates $(50 \mu \mathrm{g})$ were resolved by $10 \%$ SDS-PAGE and immunoblotted with anti-phosphoT308- or anti-phosphoS473-Akt antibody as indicated. Representative immunoblots of two independent experiments are shown. c Cells were incubated for 20 min with or without $25 \mathrm{nmol} / 1$ wortmannin prior to and during the stimulation with $5 \mu \mathrm{g} / \mathrm{ml}$ troglitazone or $100 \mathrm{nmol} / 1$ insulin for $30 \mathrm{~min}$. 2-Deoxyglucose glucose uptake was determined over a 5-min period and the net effect of each condition over basal glucose uptake (control) is shown. Results are the means $\pm \mathrm{SE}$ of six independent experiments. $* * * p<0.001$ vs insulin alone. Co Control, Tro troglitazone

creases glucose uptake into skeletal muscle. However, the stimulation of AMPK cannot always be linked to a rise in glucose uptake. For example, hypoxia, contraction and AICAR activate AMPK, but expression of a dominantnegative mutant of AMPK (AMPK $\alpha$ K45R) has minor effects on glucose uptake induced by muscle contraction while fully preventing the stimulation of glucose uptake induced by hypoxia and AICAR [54]. Similarly, gene deletions of AMPK $\alpha 1$ or $\alpha 2$ subunits in mice are without effect on contraction-stimulated glucose uptake $[19,55]$. In L6GLUT4myc cells, hyperosmolarity and DNP elevate AMPK and glucose uptake, yet calcium-dependent mechanisms including activation of protein kinase $\mathrm{C}$ mediate the majority of the increase in glucose uptake by these stimuli [33]. Hence, any stimulus that boosts both AMPK and glucose uptake has to be tested for the causal relationship between these parameters. In the present study, we used siRNA to interfere with AMPK activation in response to troglitazone. This approach significantly and selectively inhibited troglitazone-stimulated AMPK, and in parallel diminished the stimulation of glucose flux by the drug. These observations establish a causative role for AMPK in troglitazone-stimulated 2-deoxyglucose uptake in muscle cells.

Mechanism of increased hexose uptake by AMPK in muscle The cellular mechanism through which activated AMPK leads to increased 2-deoxyglucose uptake in response to various stimuli is unclear. The rise in muscle glucose uptake provoked by hypoxia is brought about by translocation of GLUT4 to the plasma membrane [56]. This response is curbed in muscles expressing a dominant-negative AMPK $\alpha$ K45R mutant transgene [54], establishing that in response to hypoxia AMPK elicits GLUT4 mobilisation. In contrast to hypoxia, AICAR increases GLUT4 translocation only modestly compared with a much higher increase in glucose uptake $[28,57]$. These findings raise the possibility that AMPK may regulate glucose transporter activity and/or glucose metabolism in addition to glucose transporter translocation.

Here, we show that the acute stimulation of 2-deoxyglucose uptake in response to troglitazone does not involve changes in surface GLUT4 or GLUT1 (Fig. 3). An alternative explanation is that troglitazone may stimulate the activity of GLUTs already present at the plasma membrane. AMPK has been implicated in glucose transporter activation, since AMPK increases the intrinsic activity of GLUT1 in clone 9 cells $[58,59], 3 \mathrm{~T} 3-\mathrm{L} 1$ preadipocytes and $\mathrm{C} 2 \mathrm{C} 12$ myoblasts [60]. However, the stimulation of hexose uptake by troglitazone is unlikely to involve a major increase in glucose transport, since 3-O-methylglucose uptake was not elevated (Fig. 3b) and free 2-deoxyglucose was only marginally increased (Fig. 3a). Instead, hexose phosphorylation appears to be the step enhanced by troglitazone, with an ensuing increase in the intracellular 2-DGP/free 2-deoxyglucose ratio (Fig. 4b, c).

Is hexokinase activity affected by AMPK? AMPK activation can induce gene expression of hexokinase II, an isoform expressed in muscle [61]. However, given the short duration of troglitazone stimulation in the present study (30 min) it is unlikely that sufficient hexokinase II biosynthesis occurs in that time to mediate the stimulation of 2-DGP accumulation. More rapid regulation of hexokinase activity is achieved by allosteric mechanisms, most notably 
a

i.b. $\alpha 1$-AMPK

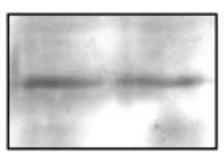

i.b. $\alpha 2$-AMPK

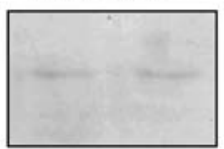

C
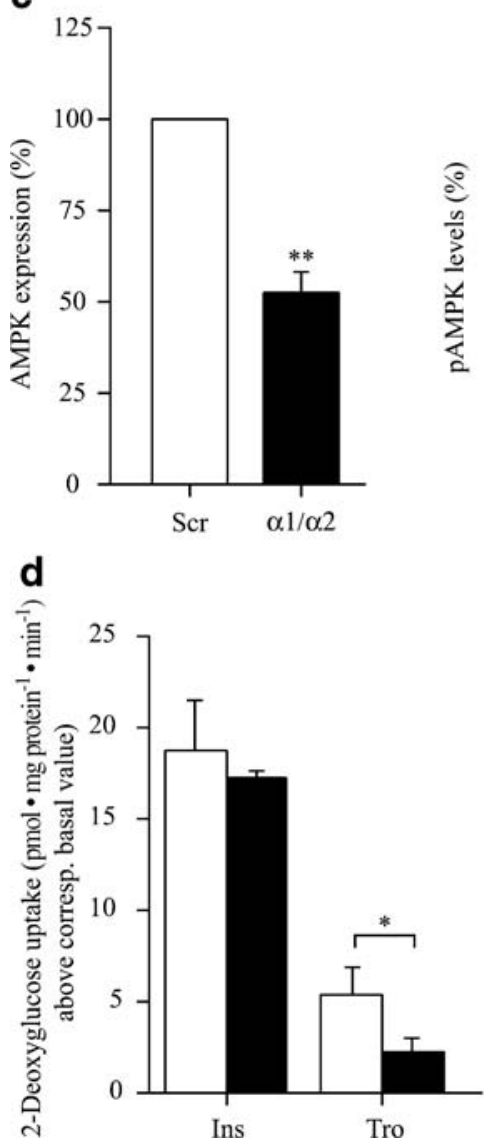

Fig. 6 Gene silencing of AMPK reduces troglitazone-mediated increase in 2-deoxyglucose uptake. L6GLUT4myc myotubes were transfected with oligofectamine (Oligo) only, unrelated siRNA, or a combination of two siRNAs sequences directed against the two $\alpha$ isoforms of AMPK (AMPK $\alpha 1 / \alpha 2$-siRNA) for $48 \mathrm{~h}$. a Expression of $\alpha 1$ and $\alpha 2$ isoforms of AMPK in L6 GLUT4myc myotubes. The isoform-specific $\alpha 1$ and $\alpha 2$ AMPK antibodies have been previously characterised [67]. Both antibodies recognise a protein band of approximately $63 \mathrm{M}_{\mathrm{r}}$. b L6GLUT4myc myotubes were incubated with or without $5 \mu \mathrm{g} / \mathrm{ml}$ troglitazone for $10 \mathrm{~min}$. Lysates $(50 \mu \mathrm{g})$ were resolved by $10 \%$ SDS-PAGE and immunoblotted with antiAMPK $\alpha 1 / \alpha 2$ antibody or anti-phosphoT172-AMPK $\alpha$ antibody. The upper panel shows one representative blot of AMPK $\alpha 1 / \alpha 2$ in cell lysates from untreated controls for all four conditions. The lower panel shows one representative blot of phospho-AMPK levels in cell b

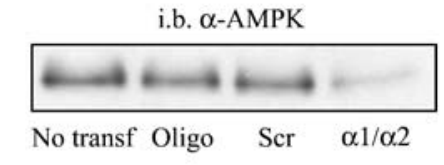

i.b. a-phospho (Thr 172) AMPK

\begin{tabular}{|cccc|}
\hline & \multicolumn{3}{c|}{} \\
\hline Co Tro & Co Tro & Co Tro & Co Tro \\
No transf & Oligo & Scr & $\alpha 1 / \alpha 2$
\end{tabular}
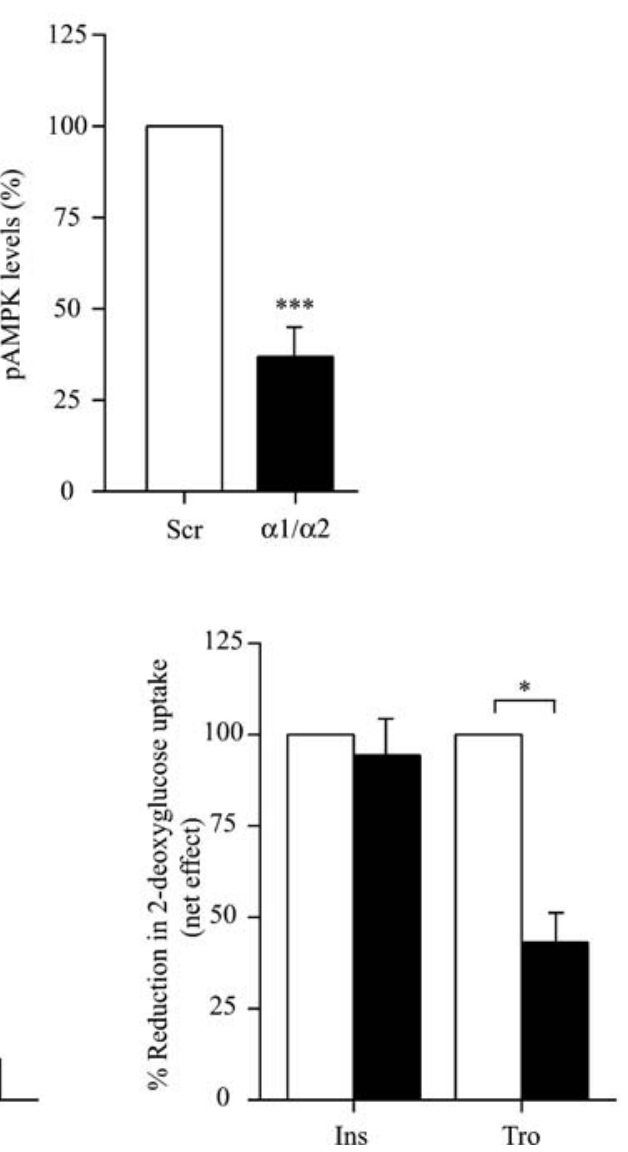

lysates from untreated controls and troglitazone-treated cells for all four conditions. c Immunoblots (i.b.) like those shown in $\mathbf{b}$ were scanned within the linear range and quantified using the computer software NIH Image. The quantified values (upper and lower panels) represent the means $\pm \mathrm{SE}$ of four experiments and are expressed relative to AMPK expression in myotubes transfected with unrelated siRNA (Scr), the latter being assigned a value of $100 \%$. $* * p<0.01$ and $* * * p<0.001$ vs nontransfected myotubes. d Cells were stimulated with $5 \mu \mathrm{g} / \mathrm{ml}$ troglitazone or with $100 \mathrm{nmol} / 1$ insulin (Ins) for $30 \mathrm{~min}$. 2-Deoxyglucose glucose uptake was determined over a 5min period. Shown is the net increase in 2-deoxyglucose uptake above basal in response to each stimulus in myotubes transfected either with unrelated siRNA (open bars) or with AMPK $\alpha 1 / \alpha 2$ siRNA (filled bars). Results are the means \pm SE of six independent experiments. ${ }^{*} p<0.05$. Co Control, Tro troglitazone 
Fig. 7 Mitochondrial membrane depolarisation in response to troglitazone is independent of AMPK. L6GLUT4myc myotubes grown on glass coverslips were transfected with oligofectamine only, unrelated (Unr) siRNA, or combination of two siRNA sequences directed against the two alpha isoforms of AMPK (AMPK $\alpha 1 / \alpha 2$ -

siRNA) for $48 \mathrm{~h}$. The cells were then serum starved for $3 \mathrm{~h}$, and $1 \mu \mathrm{g} / \mathrm{ml} \mathrm{JC}-1$. Following treatment with JC-1, the cells were rinsed and subjected to live-cell scribed in Materials and methand after treatment with $5 \mu \mathrm{g} / \mathrm{ml}$ (11 $\mu \mathrm{mol} / \mathrm{l})$ troglitazone for $10 \mathrm{~min}$. The ratio of red/green fluorescence intensity was obtained during acquisition and is presented in gray scale. Shown in $\mathbf{a}$ are representative confocal images for each condition. b Quantitation of the red/green fluorescence ratio, expressed relative to that in control cells treated with unrelated siRNA. $* * p<0.01$ vs basal-Unr siRNA preincubated for $20 \mathrm{~min}$ with confocal microscopy as deods. Images were taken before
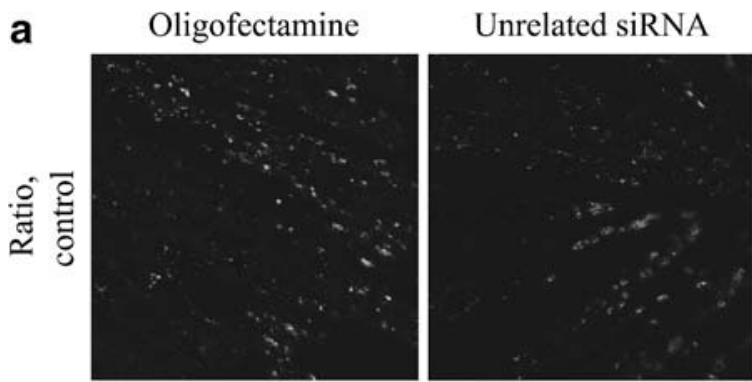

$\alpha 1 / \alpha 2$ siRNA
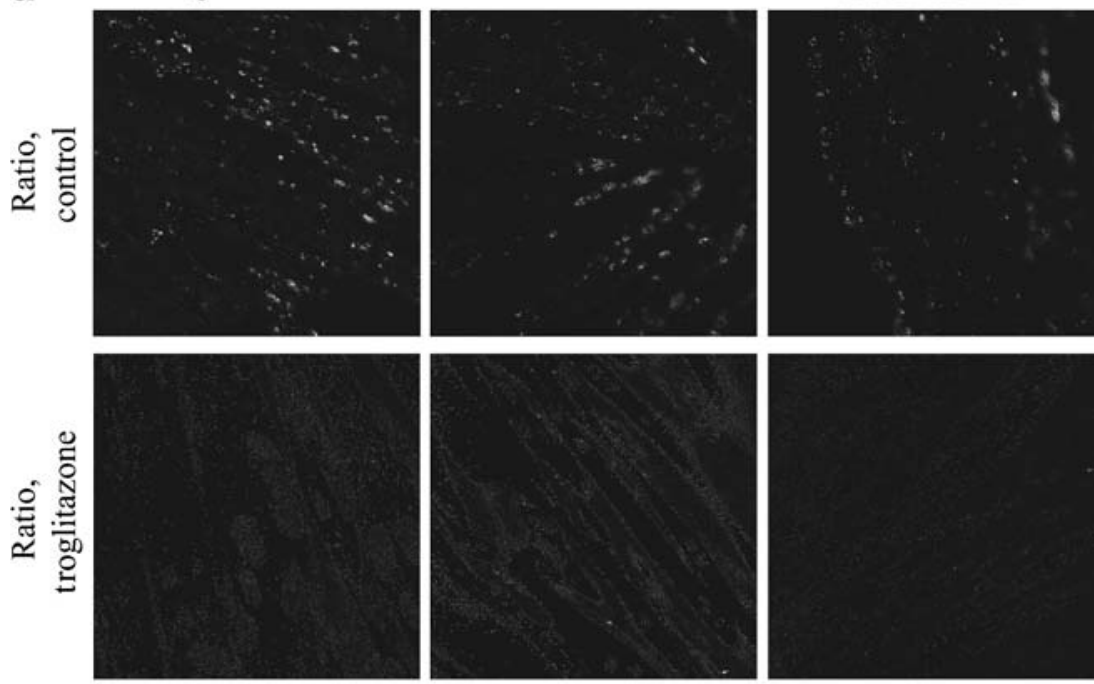

b

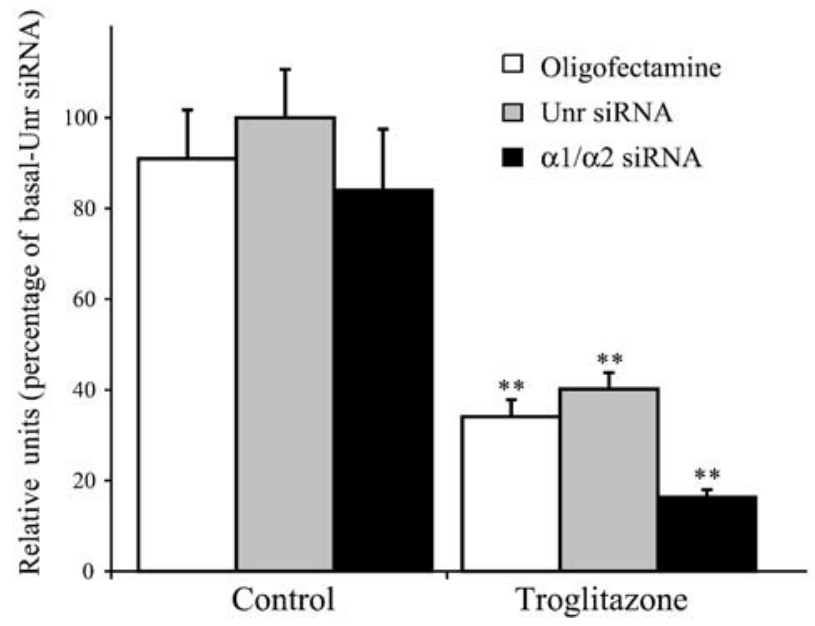

product inhibition by glucose-6-phosphate. AMPK accelerates glycolytic flux by directly phosphorylating and activating phosphofructokinase 2 in cardiomyocytes, monocytes and astrocytes [62-64]. The ensuing increase in fructose2,6-bisphosphate and the resulting allosteric stimulation of phosphofructokinase 1 increases the utilisation of glucose6-phosphate, thus relieving an inhibitory allosteric input on hexokinase. However, it is generally thought that skeletal muscle expresses an isoform of phosphofructokinase 2 (PFK2) that cannot be regulated by AMPK. Interestingly, using RT-PCR we detected mRNA for the AMPK-regulatable cardiac and brain isoforms of PFK2 in skeletal muscle isolated from rat and mouse, as well as in L6 myotubes (Liu et al., unpublished observations).

We therefore hypothesise that troglitazone may relieve inhibition of hexokinase via input from AMPK during the $30 \mathrm{~min}$ of incubation. Indeed, we observed an increase in the 2-DGP/2-deoxyglucose ratio in the uptake assay following the incubation of cells with troglitazone (Fig. 4c), suggesting that troglitazone increased hexokinase flux. This result is in agreement with previous studies suggesting that
TZDs acutely accelerate glycolytic flux in muscle and astrocytes, resulting in heightened glucose consumption and lactate production $[6,64,65]$. With our current finding of mitochondria membrane depolarisation by troglitazone, these metabolic adaptations are consistent with the Pasteur effect, in which glycolytic energy production is enhanced to compensate for a deficiency in ATP derived from mitochondrial respiration.

In conclusion, muscle cells respond to the TZD troglitazone with acute mitochondrial membrane depolarisation and activation of AMPK. AMPK then mediates a troglitazone-induced increase in glucose flux, presumably relieving inhibition at the level of hexokinase. Future work should examine the molecular events underlying the regulation of glycolysis through AMPK in response to troglitazone, as well as in response to exercise, a condition in which glucose phosphorylation may become rate-limiting for glucose utilisation by skeletal muscle [66].

What is the implication of the results presented here in our understanding of the therapeutic effects of troglitazone achieved through chronic drug administration? We hy- 
pothesise that by challenging mitochondrial energy production, thiazolidinediones induce compensatory mechanisms yielding favourable metabolic effects. These would include the early increase in hexose flux described here, as well as the known effects on gene expression (e.g. on GLUT4, hexokinase II, etc.), on GLUT4 localisation in muscle and on mitochondrial biogenesis. It is also plausible that toxic side effects of thiazolidinediones may arise when the challenge on mitochondrial function exceeds the compensatory mechanisms. The overall benefit to the patient would clearly be the resultant of all of the diverse responses to the drugs.

Acknowledgements We thank M. Hayashi for excellent assistance in early parts of this study. This work was supported by a grant to A. Klip from the Canadian Diabetes Association. L.A. Witters is supported by a grant from the National Institutes of Health (DK35712). D. Konrad was supported by a fellowship from the Swiss National Science Foundation (grant no. 81ZH-57433), by the Research Institute of The Hospital for Sick Children (Clinician Scientist Award), and by the Zürcher Diabetes-Gesellschaft. A. Rudich was supported in part by the Albert Renold Career Development Award from the European Foundation for the Study of Diabetes, and by a postdoctoral fellowship from the Research Training Centre, The Hospital for Sick Children. N. Patel was supported by a studentship from the Banting and Best Diabetes Center at the University of Toronto.

Duality of interest

The authors declare that they have no conflict of interest pertaining this communication.

\section{References}

1. Olefsky JM, Saltiel AR (2000) PPAR gamma and the treatment of insulin resistance. Trends Endocrinol Metab 11:362-368

2. Rosen ED, Spiegelman BM (2001) PPARgamma: a nuclear regulator of metabolism, differentiation, and cell growth. J Biol Chem 276:37731-37734

3. Kim JK, Fillmore JJ, Gavrilova O et al (2003) Differential effects of rosiglitazone on skeletal muscle and liver insulin resistance in A-ZIP/F-1 fatless mice. Diabetes 52:1311-1318

4. Burant CF, Sreenan S, Hirano K et al (1997) Troglitazone action is independent of adipose tissue. J Clin Invest 100:2900-2908

5. Okuno A, Ikeda K, Shiota M et al (1997) Acute effect of troglitazone on glucose metabolism in the absence or presence of insulin in perfused rat hindlimb. Metabolism 46:716-721

6. Furnsinn C, Neschen S, Noe C et al (1997) Acute non-insulinlike stimulation of rat muscle glucose metabolism by troglitazone in vitro. Br J Pharmacol 122:1367-1374

7. Norris AW, Chen L, Fisher SJ et al (2003) Muscle-specific PPARgamma-deficient mice develop increased adiposity and insulin resistance but respond to thiazolidinediones. J Clin Invest 112:608-618

8. Hevener AL, He W, Barak Y et al (2003) Muscle-specific PPARg deletion causes insulin resistance. Nat Med 9:1491-1497

9. Graham DJ, Drinkard CR, Shatin D (2003) Incidence of idiopathic acute liver failure and hospitalized liver injury in patients treated with troglitazone. Am J Gastroenterol 98:175-179

10. Parker JC (2002) Troglitazone: the discovery and development of a novel therapy for the treatment of Type 2 diabetes mellitus. Adv Drug Deliv Rev 54:1173-1197

11. Shishido S, Koga H, Harada M et al (2003) Hydrogen peroxide overproduction in megamitochondria of troglitazone-treated human hepatocytes. Hepatology 37:136-147

12. Narayanan PK, Hart T, Elcock F et al (2003) Troglitazoneinduced intracellular oxidative stress in rat hepatoma cells: a flow cytometric assessment. Cytometry 52:28-35
13. Bashan N, Burdett E, Hundal HS, Klip A (1992) Regulation of glucose transport and GLUT1 glucose transporter expression by $\mathrm{O} 2$ in muscle cells in culture. Am J Physiol 262:C682-C690

14. Bashan N, Burdett E, Guma A et al (1993) Mechanisms of adaptation of glucose transporters to changes in the oxidative chain of muscle and fat cells. Am J Physiol 264:C430-C440

15. Shetty M, Loeb JN, Ismail-Beigi F (1992) Enhancement of glucose transport in response to inhibition of oxidative metabolism: pre- and posttranslational mechanisms. Am J Physiol 262:C527-C532

16. Konrad D, Somwar R, Sweeney G et al (2001) The antihyperglycemic drug alpha-lipoic acid stimulates glucose uptake via both GLUT4 translocation and GLUT4 activation: potential role of p38 mitogen-activated protein kinase in GLUT4 activation. Diabetes 50:1464-1471

17. Zierath JR (2002) Invited review: exercise training-induced changes in insulin signaling in skeletal muscle. J Appl Physiol 93:773-781

18. Sakamoto K, Goodyear LJ (2002) Invited review: intracellular signaling in contracting skeletal muscle. J Appl Physiol 93: 369-383

19. Wojtaszewski JF, Nielsen JN, Jorgensen SB, Frosig C, Birk JB, Richter EA (2003) Transgenic models - a scientific tool to understand exercise-induced metabolism: the regulatory role of AMPK (5'-AMP-activated protein kinase) in glucose transport and glycogen synthase activity in skeletal muscle. Biochem Soc Trans 31:1290-1294

20. Carling D, Fryer LG, Woods A, Daniel T, Jarvie SL, Whitrow H (2003) Bypassing the glucose/fatty acid cycle: AMP-activated protein kinase. Biochem Soc Trans 31:1157-1160

21. Shaw RJ, Kosmatka M, Bardeesy N et al (2004) The tumor suppressor LKB1 kinase directly activates AMP-activated kinase and regulates apoptosis in response to energy stress. Proc Natl Acad Sci U S A 101:3329-3335

22. Woods A, Johnstone SR, Dickerson K et al (2003) LKB1 is the upstream kinase in the AMP-activated protein kinase cascade. Curr Biol 13:2004-2008

23. Hawley SA, Boudeau J, Reid JL et al (2003) Complexes between the LKB1 tumor suppressor, STRADalpha/beta and MO25alpha/beta are upstream kinases in the AMP-activated protein kinase cascade. J Biol 2:28

24. Hardie DG, Hawley SA (2001) AMP-activated protein kinase: the energy charge hypothesis revisited. BioEssays 23:1112-1119

25. McGarry JD (2002) Banting lecture 2001: dysregulation of fatty acid metabolism in the etiology of type 2 diabetes. Diabetes 51:7-18

26. Koistinen HA, Zierath JR (2002) Regulation of glucose transport in human skeletal muscle. Ann Med 34:410-418

27. Hayashi T, Hirshman MF, Fujii N, Habinowski SA, Witters LA, Goodyear LJ (2000) Metabolic stress and altered glucose transport: activation of AMP-activated protein kinase as a unifying coupling mechanism. Diabetes 49:527-531

28. Kurth-Kraczek EJ, Hirshman MF, Goodyear LJ, Winder WW (1999) 5' AMP-activated protein kinase activation causes GLUT4 translocation in skeletal muscle. Diabetes 48:1667-1671

29. Vavvas D, Apazidis A, Saha AK et al (1997) Contraction-induced changes in acetyl-CoA carboxylase and 5'-AMP-activated kinase in skeletal muscle. J Biol Chem 272:13255-13261

30. Wang Q, Khayat Z, Kishi K, Ebina Y, Klip A (1998) GLUT4 translocation by insulin in intact muscle cells: detection by a fast and quantitative assay. FEBS Lett 427:193-197

31. Reers M, Smith TW, Chen LB (1991) J-aggregate formation of a carbocyanine as a quantitative fluorescent indicator of membrane potential. Biochemistry 30:4480-4486

32. Yaworsky K, Somwar R, Ramlal T, Tritschler HJ, Klip A (2000) Engagement of the insulin-sensitive pathway in the stimulation of glucose transport by alpha-lipoic acid in 3T3-L1 adipocytes. Diabetologia 43:294-303 
33. Patel N, Khayat ZA, Ruderman NB, Klip A (2001) Dissociation of 5' AMP-activated protein kinase activation and glucose uptake stimulation by mitochondrial uncoupling and hyperosmolar stress: differential sensitivities to intracellular $\mathrm{Ca} 2+$ and protein kinase C inhibition. Biochem Biophys Res Commun 285:10661070

34. Sweeney G, Somwar R, Ramlal T, Volchuk A, Ueyama A, Klip A (1999) An inhibitor of p38 mitogen-activated protein kinase prevents insulin-stimulated glucose transport but not glucose transporter translocation in 3T3-L1 adipocytes and L6 myotubes. J Biol Chem 274:10071-10078

35. Jacobs AE, Oosterhof A, Veerkamp JH (1990) 2-Deoxy-Dglucose uptake in cultured human muscle cells. Biochim Biophys Acta 1051:230-236

36. Ray J, Noll F, Daut J, Hanley PJ (2002) Long-chain fatty acids increase basal metabolism and depolarize mitochondria in cardiac muscle cells. Am J Physiol Heart Circ Physiol 282: H1495-H1501

37. Sherratt HS (1991) Mitochondria: structure and function. Rev Neurol (Paris) 147:417-430

38. Kudo S, Morigaki R, Saito J, Ikeda M, Oka K, Tanishita K (2000) Shear-stress effect on mitochondrial membrane potential and albumin uptake in cultured endothelial cells. Biochem Biophys Res Commun 270:616-621

39. Cazzalini O, Lazze MC, Iamele L et al (2001) Early effects of AZT on mitochondrial functions in the absence of mitochondrial DNA depletion in rat myotubes. Biochem Pharmacol 62:893-902

40. Fryer LG, Parbu-Patel A, Carling D (2002) The anti-diabetic drugs rosiglitazone and metformin stimulate AMP-activated protein kinase through distinct signaling pathways. J Biol Chem 277:25226-25232

41. Saha AK, Avilucea PR, Ye JM, Assifi MM, Kraegen EW, Ruderman NB (2004) Pioglitazone treatment activates AMPactivated protein kinase in rat liver and adipose tissue in vivo. Biochem Biophys Res Commun 314:580-585

42. Hayashi T, Hirshman MF, Kurth EJ, Winder WW, Goodyear LJ (1998) Evidence for 5' AMP-activated protein kinase mediation of the effect of muscle contraction on glucose transport. Diabetes 47:1369-1373

43. Musi N, Hayashi T, Fujii N, Hirshman MF, Witters LA, Goodyear LJ (2001) AMP-activated protein kinase activity and glucose uptake in rat skeletal muscle. Am J Physiol Endocrinol Metab 280:E677-E684

44. Burant CF, Bell GI (1992) Mammalian facilitative glucose transporters: evidence for similar substrate recognition sites in functionally monomeric proteins. Biochemistry 31:1041410420

45. Keller K, Strube M, Mueckler M (1989) Functional expression of the human HepG2 and rat adipocyte glucose transporters in Xenopus oocytes. Comparison of kinetic parameters. J Biol Chem 264:18884-18889

46. Nishimura H, Pallardo FV, Seidner GA, Vannucci S, Simpson IA, Birnbaum MJ (1993) Kinetics of GLUT1 and GLUT4 glucose transporters expressed in Xenopus oocytes. J Biol Chem 268: $8514-8520$

47. Majewski N, Nogueira V, Robey RB, Hay N (2004) Akt inhibits apoptosis downstream of BID cleavage via a glucosedependent mechanism involving mitochondrial hexokinases. Mol Cell Biol 24:730-740

48. He W, Barak Y, Hevener A et al (2003) Adipose-specific peroxisome proliferator-activated receptor gamma knockout causes insulin resistance in fat and liver but not in muscle. Proc Natl Acad Sci U S A 100:15712-15717

49. Chinopoulos C, Tretter L, Adam-Vizi V (1999) Depolarization of in situ mitochondria due to hydrogen peroxide-induced oxidative stress in nerve terminals: inhibition of alpha-ketoglutarate dehydrogenase. J Neurochem 73:220-228

50. Furnsinn C, Brunmair B, Neschen S, Roden M, Waldhausl W (2000) Troglitazone directly inhibits $\mathrm{CO}(2)$ production from glucose and palmitate in isolated rat skeletal muscle. J Pharmacol Exp Ther 293:487-493
51. Colca JR, McDonald WG, Waldon DJ et al (2004) Identification of a novel mitochondrial protein ("mitoNEET") crosslinked specifically by a thiazolidinedione photoprobe. Am J Physiol Endocrinol Metab 286:E252-E260

52. Brunmair B, Staniek K, Gras F et al (2004) Thiazolidinediones, like metformin, inhibit respiratory complex I: a common mechanism contributing to their antidiabetic actions? Diabetes 53: $1052-1059$

53. Winder WW, Hardie DG (1999) AMP-activated protein kinase, a metabolic master switch: possible roles in type 2 diabetes. Am J Physiol 277:E1-E10

54. Mu J, Brozinick JT Jr, Valladares O, Bucan M, Birnbaum MJ (2001) A role for AMP-activated protein kinase in contractionand hypoxia-regulated glucose transport in skeletal muscle. Mol Cell 7:1085-1094

55. Jorgensen SB, Viollet B, Andreelli F et al (2004) Knockout of the alpha2 but not alpha1 5'-AMP-activated protein kinase isoform abolishes 5-aminoimidazole-4-carboxamide-1-beta-4ribofuranosidebut not contraction-induced glucose uptake in skeletal muscle. J Biol Chem 279:1070-1079

56. Cartee GD, Douen AG, Ramlal T, Klip A, Holloszy JO (1991) Stimulation of glucose transport in skeletal muscle by hypoxia. J Appl Physiol 70:1593-1600

57. Lemieux K, Konrad D, Klip A, Marette A (2003) The AMPactivated protein kinase activator AICAR does not induce GLUT4 translocation to transverse tubules but stimulates glucose uptake and p38 mitogen-activated protein kinases alpha and beta in skeletal muscle. FASEB J 17:1658-1665

58. Xi X, Han J, Zhang JZ (2001) Stimulation of glucose transport by AMP-activated protein kinase via activation of $\mathrm{p} 38$ mitogenactivated protein kinase. J Biol Chem 276:41029-41034

59. Barnes K, Ingram JC, Porras $\mathrm{OH}$ et al (2002) Activation of GLUT1 by metabolic and osmotic stress: potential involvement of AMP-activated protein kinase (AMPK). J Cell Sci 115:24332442

60. Abbud W, Habinowski S, Zhang JZ et al (2000) Stimulation of AMP-activated protein kinase (AMPK) is associated with enhancement of Glut1-mediated glucose transport. Arch Biochem Biophys 380:347-352

61. Stoppani J, Hildebrandt AL, Sakamoto K, Cameron-Smith D, Goodyear LJ, Neufer PD (2002) AMP-activated protein kinase activates transcription of the UCP3 and HKII genes in rat skeletal muscle. Am J Physiol Endocrinol Metab 283:E1239E1248

62. Marsin AS, Bertrand L, Rider MH et al (2000) Phosphorylation and activation of heart PFK-2 by AMPK has a role in the stimulation of glycolysis during ischaemia. Curr Biol 10:12471255

63. Marsin AS, Bouzin C, Bertrand L, Hue L (2002) The stimulation of glycolysis by hypoxia in activated monocytes is mediated by AMP-activated protein kinase and inducible 6phosphofructo-2-kinase. J Biol Chem 277:30778-30783

64. Almeida A, Moncada S, Bolanos JP (2004) Nitric oxide switches on glycolysis through the AMP protein kinase and 6-phosphofructo-2-kinase pathway. Nat Cell Biol 6:45-51

65. Dello Russo C, Gavrilyuk V, Weinberg G et al (2003) Peroxisome proliferator-activated receptor gamma thiazolidinedione agonists increase glucose metabolism in astrocytes. J Biol Chem 278: $5828-5836$

66. Fueger PT, Bracy DP, Malabanan CM, Pencek RR, Wasserman DH (2004) Distributed control of glucose uptake by working muscles of conscious mice: roles of transport and phosphorylation. Am J Physiol Endocrinol Metab 286:E77-E84

67. Chen ZP, Mitchelhill KI, Michell BJ et al (1999) AMPactivated protein kinase phosphorylation of endothelial $\mathrm{NO}$ synthase. FEBS Lett 443:285-289 